\title{
SO and CS observations of molecular clouds ${ }^{\star}$
}

\section{The observational data}

\author{
A. Nilsson, P. Bergman, and Å. Hjalmarson \\ Onsala Space Observatory, SE-439 92 Onsala, Sweden
}

Received August 24, 1999; accepted March 14, 2000 to current knowledge from modelling of interstellar chemistry the main formation and destruction routes for $\mathrm{O}_{2}$ and $\mathrm{SO}$ are very similar. $\mathrm{O}_{2}$ and $\mathrm{SO}$ are formed in reactions between $\mathrm{O}$ or $\mathrm{S}$ with $\mathrm{OH}$, and are destroyed by reactions with $\mathrm{C}$ as long as carbon is abundant. This means that the $\mathrm{O}_{2}$ and $\mathrm{SO}$ abundances are expected to stay low at early times and that both abundances will rapidly increase to a rather constant level when most $\mathrm{C}$ has been locked up in the formation of CO (e.g. Graedel et al. 1982; Prasad \& Huntress 1982; Millar \& Nejad 1985; Millar \& Herbst 1990; Millar et al. 1991; Bergin et al. 1995; Bergin et al. 1997; Millar et al. 1997). Hence our second goal is to study observationally and by chemical modelling what is causing eventual abundance variations of $\mathrm{SO}$ and $\mathrm{O}_{2}$.

The observational part of this work is based upon the $\mathrm{SO} / \mathrm{CS}$ abundance ratio maps derived from observations of the $\mathrm{SO}\left(3_{2}-2_{1}\right)$ and $\mathrm{CS}(2-1)$ at $99.3 \mathrm{GHz}$ and $98.0 \mathrm{GHz}$, respectively, supplemented by ${ }^{34} \mathrm{SO}\left(3_{2}-2_{1}\right)$ and $\mathrm{C}^{34} \mathrm{~S}(2-1)$ observations to handle optical depth problems. The reason why we are "normalizing" with CS is that this species - according to the chemical models - is rising to a high abundance already at early times and then stays rather constant in time. The SO and CS transitions selected have rather similar upper state energies and excitation requirements. These questions will be treated in a subsequent paper (Nilsson et al. 2000, Paper II).

The organisation of this article is as follows. In Sect. 2 we describe the details of the observations and in Sect. 3 all the mapping data are presented as SO and CS integrated intensity contour maps. In crucial positions the lines ${ }^{34} \mathrm{SO}, \mathrm{C}^{34} \mathrm{~S}, \mathrm{CS}$, and SO spectra are also shown.

\section{Observations and data reduction}

The observations were performed during several extended sessions ranging from May 95 to June 98 with the
Send offprint requests to: Å. Hjalmarson,

e-mail: hjalmar@oso.chalmers.se

* Figs. 1 to 9 are only available at http://www.edpsciences.org 
Table 1. Source list

\begin{tabular}{|c|c|c|c|c|c|c|}
\hline \multirow[t]{2}{*}{ Source } & \multicolumn{2}{|c|}{ Position } & \multirow{2}{*}{$\begin{array}{r}V_{\mathrm{LSR}} \\
\left(\mathrm{kms}^{-1}\right)\end{array}$} & \multirow{2}{*}{$\begin{array}{c}\text { Adopted distance } \\
(\mathrm{kpc})\end{array}$} & \multicolumn{2}{|c|}{ Reference } \\
\hline & $\alpha(\mathrm{B} 1950.0)$ & $\delta(\mathrm{B} 1950.0)$ & & & Distance & Molecular \\
\hline W3(IRS4) & $02^{\mathrm{h}} 21^{\mathrm{m}} 43^{\mathrm{s}} .5$ & $+61^{\circ} 52^{\prime} 49^{\prime \prime}$ & -43.0 & 2.4 & 1,2 & \\
\hline $\mathrm{W} 3(\mathrm{OH})$ & $02^{\mathrm{h}} 23^{\mathrm{m}} 17^{\mathrm{s}} .0$ & $+61^{\circ} 38^{\prime} 53^{\prime \prime}$ & -48.0 & 2.4 & 1,2 & \\
\hline NGC 1333 & $03^{\mathrm{h}} 25^{\mathrm{m}} 58.2$ & $+31^{\circ} 05^{\prime} 46^{\prime \prime}$ & +7.0 & $0.35(0.22-0.5)$ & 3 & $3,9,16,17$ \\
\hline Orion A & $05^{\mathrm{h}} 32^{\mathrm{m}} 47^{\mathrm{s}} .0$ & $-05^{\circ} 24^{\prime} 24^{\prime \prime}$ & +8.0 & 0.5 & 1 & $10,18,21$ \\
\hline OMC-2 & $05^{\mathrm{h}} 32^{\mathrm{m}} 58.3$ & $-05^{\circ} 11^{\prime} 52^{\prime \prime}$ & +10.0 & 0.5 & 1,4 & \\
\hline OMC-3 & $05^{\mathrm{h}} 32^{\mathrm{m}} 48^{\mathrm{s}} .3$ & $-05^{\circ} 02^{\prime} 10^{\prime \prime}$ & +10.0 & 0.5 & 4 & \\
\hline NGC 2023 & $05^{\mathrm{h}} 39^{\mathrm{m}} 07^{\mathrm{s}} \cdot 0$ & $-02^{\circ} 17^{\prime} 20^{\prime \prime}$ & +10.0 & 0.4 & 5 & \\
\hline NGC 2024 & $05^{\mathrm{h}} 39^{\mathrm{m}} 12^{\mathrm{s}} .8$ & $-01^{\circ} 57^{\prime} 04^{\prime \prime}$ & +10.0 & 0.4 & 5 & $9,12,13$ \\
\hline NGC 2068 & $05^{\mathrm{h}} 43^{\mathrm{m}} 34^{\mathrm{s}} .9$ & $-00^{\circ} 11^{\prime} 50^{\prime \prime}$ & +10.0 & 0.4 & 5 & 15 \\
\hline NGC 2071 & $05^{\mathrm{h}} 44^{\mathrm{m}} 30^{\mathrm{s}} \cdot 6$ & $+00^{\circ} 20^{\prime} 42^{\prime \prime}$ & +10.0 & 0.4 & 1,5 & $9,14,20,21$ \\
\hline Mon R2 & $06^{\mathrm{h}} 05^{\mathrm{m}} 22^{\mathrm{s}} .0$ & $-06^{\circ} 22^{\prime} 25^{\prime \prime}$ & +10.0 & 1.0 & 2 & \\
\hline NGC 2264IR & $06^{\mathrm{h}} 38^{\mathrm{m}} 25^{\mathrm{s}} 0$ & $+09^{\circ} 32^{\prime} 29^{\prime \prime}$ & +8.0 & 0.9 & 1 & 9 \\
\hline G $34.3+0.2$ & $18^{\mathrm{h}} 50^{\mathrm{m}} 46^{\mathrm{s}} .2$ & $+01^{\circ} 11^{\prime} 13^{\prime \prime}$ & +58.0 & 3.7 & 1,2 & \\
\hline $\mathrm{W} 49 \mathrm{~N}$ & $19^{\mathrm{h}} 07^{\mathrm{m}} 49^{\mathrm{s}} .9$ & $+09^{\circ} 01^{\prime} 17^{\prime \prime}$ & +5.0 & 11.4 & 6 & 6,20 \\
\hline $\mathrm{W} 51 \mathrm{~N}^{a}$ & $19^{\mathrm{h}} 21^{\mathrm{m}} 22^{\mathrm{s}} .4$ & $+14^{\circ} 25^{\prime} 13^{\prime \prime}$ & +60.0 & 7.0 & 2 & \\
\hline $\mathrm{DR} 21(\mathrm{OH})^{b}$ & $20^{\mathrm{h}} 37^{\mathrm{m}} 14^{\mathrm{s}} .2$ & $+42^{\circ} 12^{\prime} 10^{\prime \prime}$ & -3.0 & 3.0 & 1,2 & \\
\hline IRAS $21391+5802$ & $21^{\mathrm{h}} 39^{\mathrm{m}} 10^{\mathrm{s}} 3$ & $+58^{\circ} 02^{\prime} 29^{\prime \prime}$ & +0.0 & 0.8 & 7 & 19 \\
\hline S 140 & $22^{\mathrm{h}} 17^{\mathrm{m}} 42^{\mathrm{s}} .0$ & $+63^{\circ} 03^{\prime} 45^{\prime \prime}$ & -7.0 & 0.9 & 8 & $8,11,12,13,21$ \\
\hline NGC $7538($ IRS1) & $23^{\mathrm{h}} 11^{\mathrm{m}} 36.5$ & $+61^{\circ} 11^{\prime} 49^{\prime \prime}$ & -57.0 & 2.8 & 2 & 20 \\
\hline
\end{tabular}

Distance references: (1) Mangum \& Wootten (1993), (2) Plume, Jaffe \& Evans II (1992), (3) Blake et al. (1995), (4) Castets \& Langer (1995), (5) Lada (1992), (6) Serabyn, Güsten \& Schulz (1993), (7) Wilking et al. (1993), (8) Zhou et al. (1994), SO references: (9) Chernin et al. (1994), (10) Friberg (1984), (11) Wilner \& Welch (1994), Multi CS transition references: (12) Mundy et al. (1986), (6) Serabyn et al. (1993), (13) Snell et al. (1984a), (14) Zhou et al. (1991), (8) Zhou et al. (1994), (16) Langer et al. (1996), Molecular outflow references: (3) Blake et al. (1995), (9) Chernin et al. (1994), (15) Edwards \& Snell (1984), (10) Friberg (1984), (17) Liseau et al. (1988), (18) Olofsson et al. (1982), (19) Patel et al. (1995), (20) Scoville et al. (1986), (21) Snell et al. (1984b), (11) Wilner \& Welch (1994).

${ }^{a}$ The W $51 \mathrm{M}$ core is located approximately at an offset $\left(40^{\prime \prime},-40^{\prime \prime}\right)$ relative to W $51 \mathrm{~N}$.

${ }^{b}$ The DR 21 core is located approximately $160^{\prime \prime}$ south of DR $21(\mathrm{OH})$.

radome-enclosed Onsala $20 \mathrm{~m}$ telescope ${ }^{1}$. The telescope is equipped with a cooled SIS receiver. The single sideband system temperatures as measured outside the atmosphere were $250-1500 \mathrm{~K}$. As backends we simultaneously used a 256 channel filterbank (bandwidth $64 \mathrm{MHz}$ ) and a 1600 channel autocorrelator (configured to a bandwidth of $40 \mathrm{MHz}$ ). The resulting velocity resolutions are $0.76 \mathrm{~km}$ $\mathrm{s}^{-1}$ and $0.076 \mathrm{~km} \mathrm{~s}^{-1}$ respectively. We used the standard chopper wheel method for calibration. All spectra were taken in a dual beam switching mode (11' beam separation) with the exception of the Orion-close sources and NGC 1333 in the $\mathrm{CS}(2-1)$ line which were frequency switched $(14-18 \mathrm{MHz}$ frequency throw). Frequent pointing checks were made towards $\mathrm{SiO}$ masers, and pointing offset for all of the observations was confined within $5^{\prime \prime}$ from the pointing model. We mapped the $\mathrm{CS}(J=2-1)(98.0 \mathrm{GHz}), \mathrm{SO}\left(J_{\mathrm{N}}=3_{2}-2_{1}\right)(99.3 \mathrm{GHz})$ lines together with transitions of the less abundant ${ }^{34} \mathrm{~S}$ isotopomers, $\mathrm{C}^{34} \mathrm{~S}$ and ${ }^{34} \mathrm{SO}$, at certain positions. The telescope FWHM beamsize is $\sim 40^{\prime \prime}$ and main beam

\footnotetext{
1 Onsala $20 \mathrm{~m}$ telescope is operated by the Swedish National Facility for Radio Astronomy, Onsala Space Observatory, at Chalmers University of Technology.
}

efficiency is 0.56 at these frequencies. Only correlator data is presented here. The integration time was initially $120 \mathrm{~s}$ per position but in all cases the observations were repeated until we achieved satisfactory signal to noise ratio. The data have been reduced by the DRP package written by M. Olberg, Onsala Space Observatory, Gaussian fitting, where relevant, and displaying was made with the XS package written by $\mathrm{P}$. Bergman, Onsala Space Observatory. A linear baseline was removed from all spectra taken in beam switching mode while a low order polynomial baseline was subtracted from the frequency switched data. Since the observations spanned over a long range in time extra effort has been put on checking consistency between scans taken at same position, line and backend at different occasions.

\section{Results}

In Table 1 all map centre coordinates and LSR velocities used are collected together with source distances (from the Sun). We here also give some relevant references to published SO, multitransition CS and outflow maps. All intensities are presented in terms of main beam 
Table 2. Integrated intensities in $\mathrm{K} \mathrm{km} \mathrm{s}^{-1}$ for certain positions and lines

\begin{tabular}{|c|c|c|c|c|c|}
\hline Source & $\begin{array}{c}\text { Offset } \\
\left({ }^{\prime \prime}, "\right)\end{array}$ & $\mathrm{SO}\left(3_{2}-2_{1}\right)$ & ${ }^{34} \mathrm{SO}\left(3_{2}-2_{1}\right)$ & $\mathrm{CS}(2-1)$ & $\mathrm{C}^{34} \mathrm{~S}(2-1)$ \\
\hline DR21 (OH) & $(0,-160)$ & $8.7(0.5)$ & $0.4(0.1)$ & $32.8(0.4)$ & $4.1(0.1)$ \\
\hline DR21 (OH) & $(0,-40)$ & $21.1(0.5)$ & & $49.5(0.4)$ & $7.8(0.1)$ \\
\hline DR21 (OH) & $(-40,0)$ & $15.2(0.5)$ & & $36.6(0.5)$ & $4.4(0.2)$ \\
\hline DR21 (OH) & $(0,0)$ & $27.8(0.3)$ & $1.4(0.1)$ & $59.6(0.3)$ & $9.0(0.1)$ \\
\hline $\mathrm{DR} 21(\mathrm{OH})$ & $(40,0)$ & $6.5(0.5)$ & & $24.0(0.5)$ & $2.2(0.2)$ \\
\hline DR21 (OH) & $(0,40)$ & $15.4(0.5)$ & & $31.4(0.7)$ & $4.2(0.2)$ \\
\hline G $34.3+0.2$ & $(0,-40)$ & $12.7(0.8)$ & & $38.9(0.5)$ & $6.9(0.6)$ \\
\hline G $34.3+0.2$ & $(-40,0)$ & $17.9(1.0)$ & & $45.9(0.5)$ & $8.8(0.6)$ \\
\hline G $34.3+0.2$ & $(0,0)$ & $24.9(0.3)$ & $1.4(0.1)$ & $62.0(0.3)$ & $12.9(0.2)$ \\
\hline G $34.3+0.2$ & $(40,0)$ & $11.4(0.8)$ & & $22.4(0.5)$ & $4.2(0.3)$ \\
\hline G $34.3+0.2$ & $(0,40)$ & $10.7(0.8)$ & & $28.2(0.5)$ & $6.0(0.4)$ \\
\hline IRAS $21391+5802$ & $(0,0)$ & $10.1(0.3)$ & $0.5(0.1)$ & $24.5(0.5)$ & $1.6(0.1)$ \\
\hline Mon R2 & $(0,0)$ & $5.6(0.2)$ & & $22.4(0.2)$ & $2.9(0.1)$ \\
\hline Mon R2 & $(0,40)$ & $4.7(0.3)$ & $0.1(0.1)$ & $26.5(0.3)$ & $2.7(0.2)$ \\
\hline NGC 1333 & $(120,-200)$ & $4.8(0.3)$ & $0.8(0.1)$ & $6.3(0.2)$ & $0.7(0.1)$ \\
\hline NGC 1333 & $(40,-160)$ & $5.6(0.3)$ & $0.3(0.1)$ & $9.2(0.2)$ & $1.0(0.1)$ \\
\hline NGC 1333 & $(80,-160)$ & $9.3(0.3)$ & $0.9(0.1)$ & $11.7(0.2)$ & $1.0(0.1)$ \\
\hline NGC 1333 & $(120,-160)$ & $8.4(0.1)$ & $1.5(0.1)$ & $6.5(0.1)$ & $1.0(0.1)$ \\
\hline NGC 1333 & $(160,-160)$ & $5.4(0.2)$ & $0.6(0.1)$ & $5.1(0.2)$ & $0.7(0.1)$ \\
\hline NGC 1333 & $(80,-120)$ & $7.8(0.2)$ & $0.7(0.1)$ & $9.3(0.2)$ & $1.6(0.1)$ \\
\hline NGC 1333 & $(120,-120)$ & $6.9(0.2)$ & $0.5(0.1)$ & $7.7(0.2)$ & $1.0(0.1)$ \\
\hline NGC 1333 & $(160,-120)$ & $3.3(0.2)$ & $0.5(0.1)$ & $5.3(0.2)$ & $0.3(0.1)$ \\
\hline NGC 1333 & $(80,-80)$ & $10.2(0.3)$ & $0.7(0.1)$ & $9.2(0.2)$ & $0.7(0.2)$ \\
\hline NGC 1333 & $(120,-80)$ & $5.1(0.3)$ & $0.5(0.2)$ & $6.2(0.2)$ & $0.4(0.1)$ \\
\hline NGC 1333 & $(40,-40)$ & $9.8(0.2)$ & $0.4(0.1)$ & $13.6(0.2)$ & $0.8(0.3)$ \\
\hline NGC 1333 & $(80,-40)$ & $10.1(0.2)$ & $0.9(0.1)$ & $10.9(0.2)$ & $1.3(0.1)$ \\
\hline NGC 1333 & $(120,-40)$ & $7.7(0.3)$ & $0.7(0.1)$ & $7.5(0.2)$ & $0.6(0.1)$ \\
\hline NGC 1333 & $(0,0)$ & $2.4(0.1)$ & $0.1(0.1)$ & $10.6(0.2)$ & $0.9(0.1)$ \\
\hline NGC 1333 & $(80,0)$ & $8.7(0.2)$ & $0.6(0.1)$ & $11.1(0.2)$ & $1.2(0.1)$ \\
\hline NGC 1333 & $(120,0)$ & $5.3(0.3)$ & $0.5(0.1)$ & $7.4(0.1)$ & $0.5(0.1)$ \\
\hline NGC 1333 & $(80,40)$ & $6.2(0.3)$ & $0.6(0.1)$ & $7.3(0.2)$ & $0.3(0.1)$ \\
\hline NGC 1333 & $(120,40)$ & $4.1(0.3)$ & $0.1(0.1)$ & $6.3(0.2)$ & $0.6(0.1)$ \\
\hline NGC 1333 & $(120,80)$ & $2.6(0.3)$ & $0.2(0.1)$ & $6.0(0.2)$ & $0.0(0.1)$ \\
\hline NGC 2023 & $(0,0)$ & $0.8(0.1)$ & & $3.7(0.3)$ & $0.1(0.1)$ \\
\hline NGC 2024 & $(0,-40)$ & $10.8(0.3)$ & $0.6(0.1)$ & $40.8(0.9)$ & $4.9(0.2)$ \\
\hline NGC 2024 & $(-40,0)$ & $4.2(0.4)$ & & $18.5(0.9)$ & $1.9(0.2)$ \\
\hline NGC 2024 & $(0,0)$ & $9.7(0.2)$ & & $31.0(0.5)$ & $4.3(0.1)$ \\
\hline NGC 2024 & $(40,0)$ & $6.3(0.4)$ & & $13.6(0.9)$ & $2.3(0.2)$ \\
\hline NGC 2024 & $(0,40)$ & $8.4(0.3)$ & $0.6(0.1)$ & $33.9(0.5)$ & $4.4(0.2)$ \\
\hline NGC 2068 & $(120,-80)$ & $4.1(0.3)$ & $0.3(0.1)$ & $3.3(0.6)$ & $0.1(0.1)$ \\
\hline NGC 2068 & $(0,0)$ & $1.5(0.1)$ & & $5.9(0.4)$ & $0.5(0.1)$ \\
\hline NGC 2071 & $(0,0)$ & $2.2(0.2)$ & & $11.1(0.3)$ & $1.9(0.1)$ \\
\hline NGC 2264IR & $(0,-40)$ & $10.2(0.3)$ & & $28.0(0.4)$ & $3.4(0.1)$ \\
\hline NGC 2264IR & $(-40,0)$ & $8.1(0.3)$ & & $27.1(0.4)$ & $2.6(0.1)$ \\
\hline NGC 2264IR & $(0,0)$ & $20.1(0.2)$ & $1.1(0.1)$ & $35.9(0.2)$ & $3.7(0.1)$ \\
\hline NGC 2264IR & $(40,0)$ & $14.4(0.3)$ & & $24.3(0.4)$ & $2.9(0.2)$ \\
\hline NGC 2264IR & $(0,40)$ & $12.4(0.3)$ & & $18.4(0.4)$ & $2.7(0.2)$ \\
\hline NGC 7538 & $(0,-40)$ & $28.8(0.4)$ & $1.4(0.1)$ & $62.1(0.5)$ & $7.5(0.2)$ \\
\hline NGC 7538 & $(-40,0)$ & $9.9(0.6)$ & & $30.7(0.6)$ & $2.2(0.2)$ \\
\hline NGC 7538 & $(0,0)$ & $14.9(0.2)$ & $0.8(0.1)$ & $53.4(0.4)$ & $6.3(0.2)$ \\
\hline NGC 7538 & $(40,0)$ & $20.5(0.5)$ & & $31.4(0.5)$ & $5.6(0.3)$ \\
\hline NGC 7538 & $(0,40)$ & $6.3(0.6)$ & & $12.4(0.5)$ & $1.2(0.1)$ \\
\hline $\mathrm{OMC}-2$ & $(0,0)$ & $2.1(0.1)$ & & $14.8(0.3)$ & $1.0(0.1)$ \\
\hline OMC-3 & $(0,0)$ & $6.9(0.3)$ & $0.0(0.1)$ & $11.9(0.5)$ & $1.1(0.1)$ \\
\hline Orion A & $(0,-80)$ & $13.9(0.3)$ & $0.3(0.3)$ & $63.4(0.8)$ & $12.8(0.4)$ \\
\hline
\end{tabular}

a(b) denotes value( $1 \sigma$ error $)$. 
Table 2. continued

\begin{tabular}{|c|c|c|c|c|c|}
\hline Source & $\begin{array}{l}\text { Offset } \\
\left({ }^{\prime \prime},{ }^{\prime \prime}\right)\end{array}$ & $\mathrm{SO}\left(3_{2}-2_{1}\right)$ & ${ }^{34} \mathrm{SO}\left(3_{2}-2_{1}\right)$ & $\mathrm{CS}(2-1)$ & $\mathrm{C}^{34} \mathrm{~S}(2-1)$ \\
\hline Orion A & $(0,-40)$ & $7.5(0.5)$ & & $48.7(0.4)$ & $4.8(0.3)$ \\
\hline Orion A & $(-40,0)$ & $4.3(0.3)$ & & $45.5(0.4)$ & $7.1(0.3)$ \\
\hline Orion A & $(0,0)$ & $5.9(0.3)$ & & $52.4(0.4)$ & $9.2(0.2)$ \\
\hline Orion A & $(40,0)$ & $5.3(0.3)$ & & $17.3(0.5)$ & $2.2(0.3)$ \\
\hline Orion A & $(0,40)$ & $6.2(0.5)$ & & $38.6(0.5)$ & $5.2(0.3)$ \\
\hline S 140 & $(0,-40)$ & $6.1(0.2)$ & & $22.2(0.3)$ & $2.0(0.2)$ \\
\hline S 140 & $(-40,0)$ & $12.5(0.2)$ & & $27.0(0.3)$ & $3.1(0.2)$ \\
\hline S 140 & $(0,0)$ & $14.0(0.1)$ & $1.8(0.2)$ & $34.8(0.2)$ & $3.9(0.2)$ \\
\hline S 140 & $(40,0)$ & $6.7(0.2)$ & & $21.9(0.3)$ & $3.0(0.2)$ \\
\hline S 140 & $(0,40)$ & $13.8(0.3)$ & & $31.2(0.4)$ & $3.6(0.2)$ \\
\hline W3(IRS4) & $(-40,-40)$ & $7.8(0.4)$ & & $24.9(0.4)$ & $2.3(0.1)$ \\
\hline W3(IRS4) & $(0,-40)$ & $17.0(0.3)$ & $0.9(0.1)$ & $50.4(0.4)$ & $6.9(0.2)$ \\
\hline W3(IRS4) & $(40,-40)$ & $14.2(0.4)$ & & $31.2(0.4)$ & $2.7(0.2)$ \\
\hline W3(IRS4) & $(-40,0)$ & $7.6(0.4)$ & & $17.4(0.4)$ & $2.2(0.2)$ \\
\hline W3(IRS4) & $(0,0)$ & $13.8(0.1)$ & & $47.5(0.2)$ & $7.2(0.1)$ \\
\hline W3(IRS4) & $(40,0)$ & $10.9(0.4)$ & & $29.8(0.4)$ & $2.3(0.2)$ \\
\hline W3(IRS4) & $(-40,40)$ & $3.5(0.3)$ & & $9.8(0.3)$ & $0.5(0.2)$ \\
\hline W3(IRS4) & $(0,40)$ & $3.7(0.4)$ & & $16.3(0.4)$ & $2.0(0.2)$ \\
\hline W3(IRS4) & $(40,40)$ & $3.2(0.4)$ & & $16.2(0.4)$ & $0.8(0.2)$ \\
\hline $\mathrm{W} 3(\mathrm{OH})$ & $(0,-40)$ & $9.1(0.3)$ & & $29.2(0.5)$ & $1.9(0.2)$ \\
\hline $\mathrm{W} 3(\mathrm{OH})$ & $(-40,0)$ & $10.2(0.3)$ & & $22.0(0.6)$ & $3.1(0.2)$ \\
\hline $\mathrm{W} 3(\mathrm{OH})$ & $(-20,0)$ & $16.2(0.4)$ & $1.1(0.1)$ & $42.7(0.6)$ & \\
\hline $\mathrm{W} 3(\mathrm{OH})$ & $(0,0)$ & $22.1(0.2)$ & $0.9(0.1)$ & $45.2(0.3)$ & $6.1(0.1)$ \\
\hline $\mathrm{W} 3(\mathrm{OH})$ & $(40,0)$ & $6.2(0.3)$ & & $20.6(0.5)$ & $1.9(0.1)$ \\
\hline $\mathrm{W} 3(\mathrm{OH})$ & $(0,40)$ & $6.4(0.3)$ & & $28.2(0.5)$ & $2.2(0.2)$ \\
\hline $\mathrm{W} 49 \mathrm{~N}$ & $(0,-40)$ & $11.3(0.5)$ & & $27.4(0.4)$ & $3.0(0.2)$ \\
\hline $\mathrm{W} 49 \mathrm{~N}$ & $(-40,0)$ & $17.6(0.4)$ & & $46.7(0.4)$ & $7.7(0.2)$ \\
\hline $\mathrm{W} 49 \mathrm{~N}$ & $(0,0)$ & $66.9(0.3)$ & $6.2(0.1)$ & $87.7(0.3)$ & $11.5(0.1)$ \\
\hline $\mathrm{W} 49 \mathrm{~N}$ & $(40,0)$ & $19.8(0.4)$ & & $45.7(0.4)$ & $5.9(0.2)$ \\
\hline $\mathrm{W} 49 \mathrm{~N}$ & $(0,40)$ & $12.3(0.4)$ & & $36.3(0.3)$ & $5.4(0.2)$ \\
\hline $\mathrm{W} 51 \mathrm{~N}$ & $(-40,-40)$ & $31.8(0.5)$ & & $88.8(0.3)$ & $13.6(0.3)$ \\
\hline $\mathrm{W} 51 \mathrm{~N}$ & $(0,-40)$ & $25.6(0.5)$ & & $94.7(0.3)$ & $15.5(0.3)$ \\
\hline $\mathrm{W} 51 \mathrm{~N}$ & $(40,-40)$ & $47.4(0.4)$ & $2.7(0.1)$ & $129.2(0.3)$ & $26.6(0.3)$ \\
\hline $\mathrm{W} 51 \mathrm{~N}$ & $(-40,0)$ & $32.4(0.5)$ & & $85.8(0.3)$ & $12.4(0.3)$ \\
\hline $\mathrm{W} 51 \mathrm{~N}$ & $(0,0)$ & $32.8(0.4)$ & $1.6(0.1)$ & $90.2(0.2)$ & $14.9(0.2)$ \\
\hline $\mathrm{W} 51 \mathrm{~N}$ & $(40,0)$ & $23.8(0.5)$ & & $71.6(0.3)$ & $12.5(0.3)$ \\
\hline $\mathrm{W} 51 \mathrm{~N}$ & $(-40,40)$ & $12.7(0.3)$ & & $44.8(0.3)$ & $3.7(0.2)$ \\
\hline $\mathrm{W} 51 \mathrm{~N}$ & $(0,40)$ & $11.6(0.3)$ & & $49.7(0.3)$ & $5.2(0.3)$ \\
\hline $\mathrm{W} 51 \mathrm{~N}$ & $(40,40)$ & $10.7(0.4)$ & & $40.0(0.3)$ & $5.3(0.3)$ \\
\hline
\end{tabular}

a(b) denotes value( $1 \sigma$ error $)$.

brightness temperature. The SO and CS data are presented in Figs. 1-8 in terms of SO and CS integrated intensity $\left(\mathrm{K} \mathrm{km} \mathrm{s}^{-1}\right)$ contour maps. For the NGC 1333 core we have also mapped in ${ }^{34} \mathrm{SO}\left(3_{2}-2_{1}\right)$ and $\mathrm{C}^{34} \mathrm{~S}(2-1)$ and the integrated intensity contour maps are shown in Fig. 2. The combined contour and greyscale maps have been displayed using bicubic interpolation of the observed values.

In the case of the obvious outflow sources, NGC 2071 and Orion A, a broad Gaussian component has been subtracted from the line profile map. This is examplified in Fig. 9 for the centre positions. In the centre position of Orion A we fitted three Gaussian components to the SO line profile, a broad outflow, the hot core, and a quiescent cloud component. We obtained essentially the same result as Friberg (1984) although he used an additional component to describe the quiescent component. In positions adjacent to the centre position both the outflow and hot core components were removed. In the other positions, further off the centre, only a weak broad outflow component was removed when visible. The hot core component cannot be discerned in the CS spectrum (Fig. 9). Total and residual integrated intensity maps are shown for both sources in Figs. 4 and 8, respectively. These two sources were the only ones where we found prominent kinematical evidences of outflow activity in their SO and CS line profiles. In several other sources, e.g. G34.3+0.2, NGC 2264IR, and NGC 7538 , there are hints of weak wing emission in the 

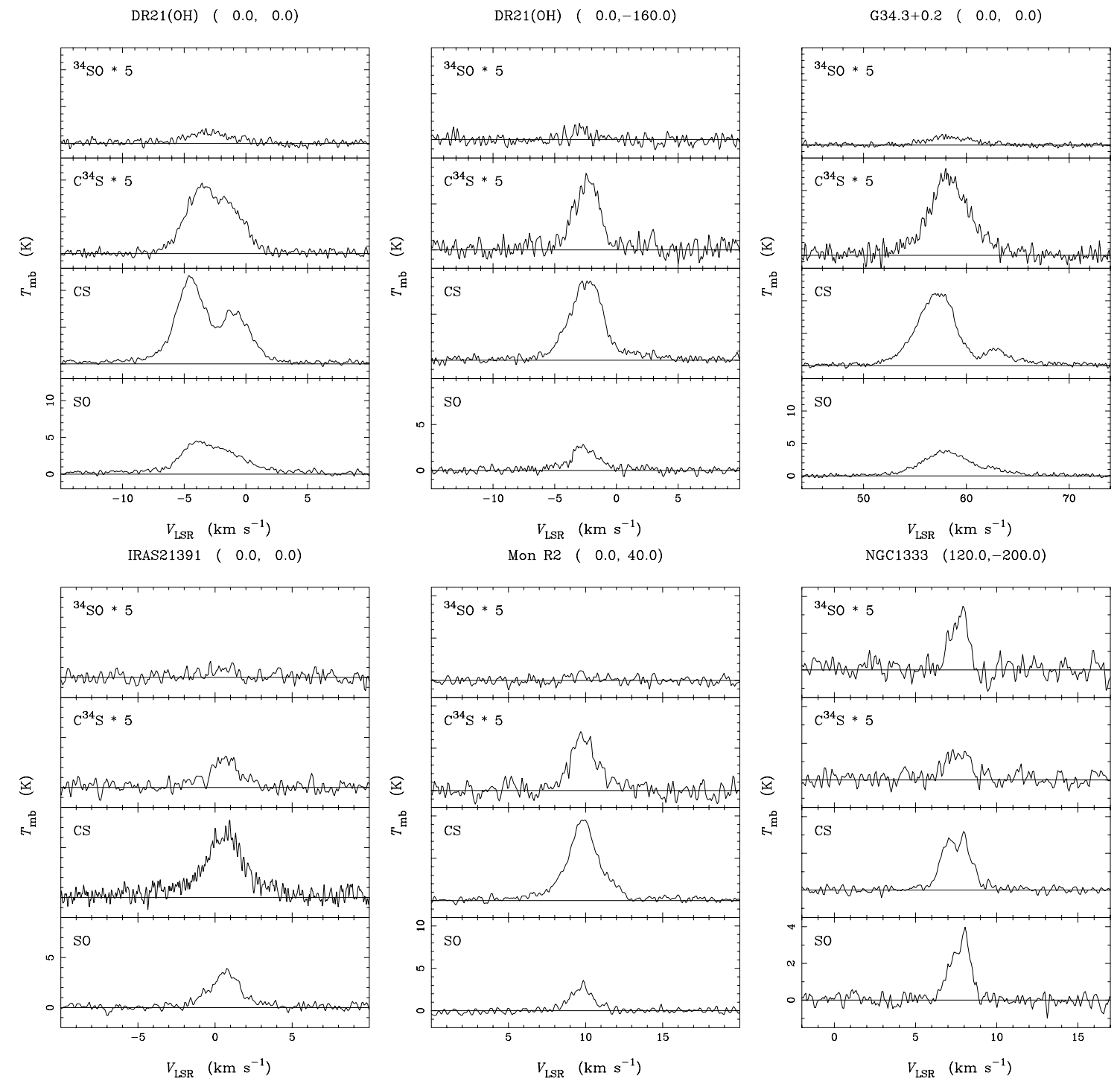

NGC1333 ( 40.0,-160.0)
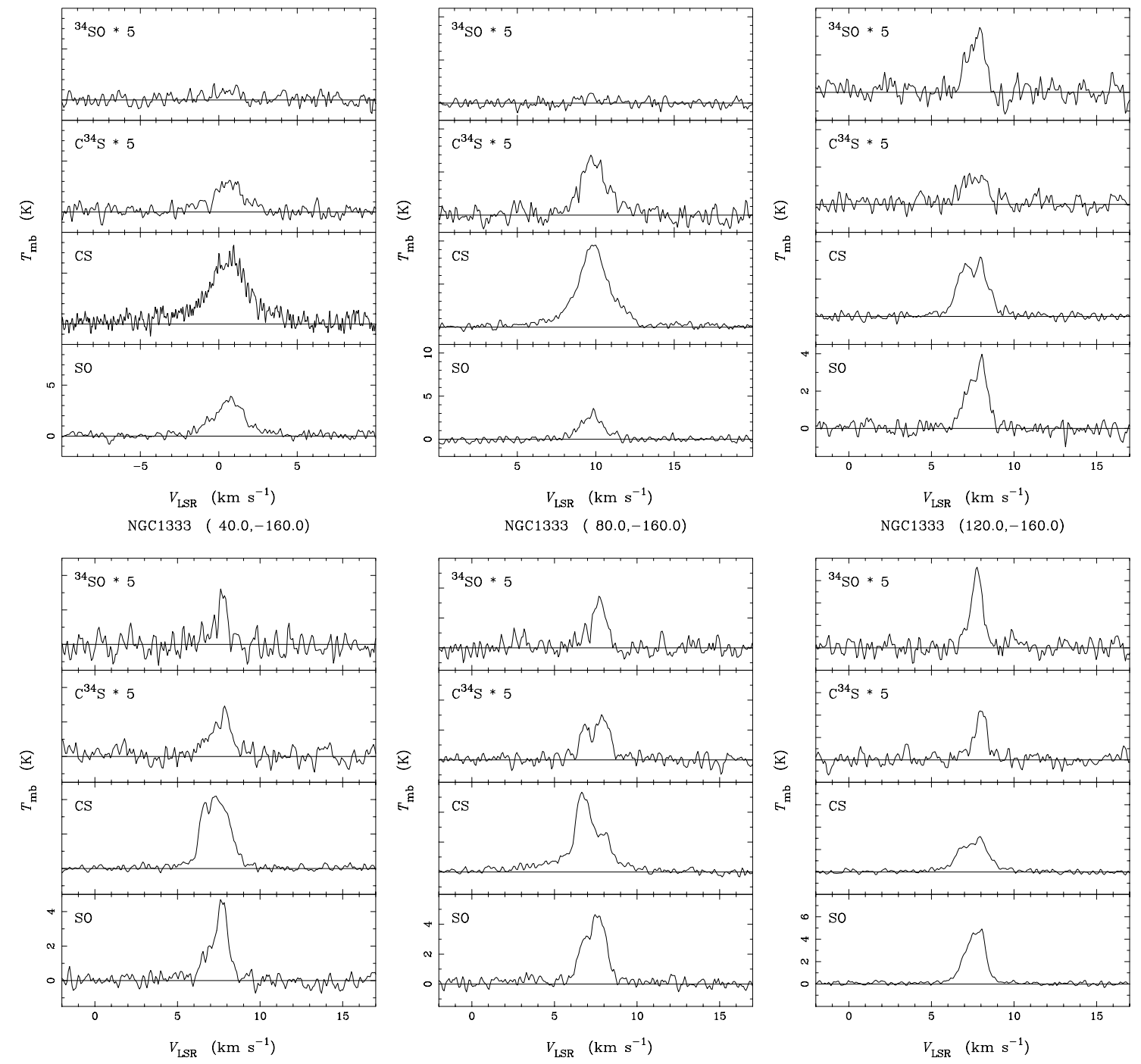

NGC1333 $(120.0,-160.0)$

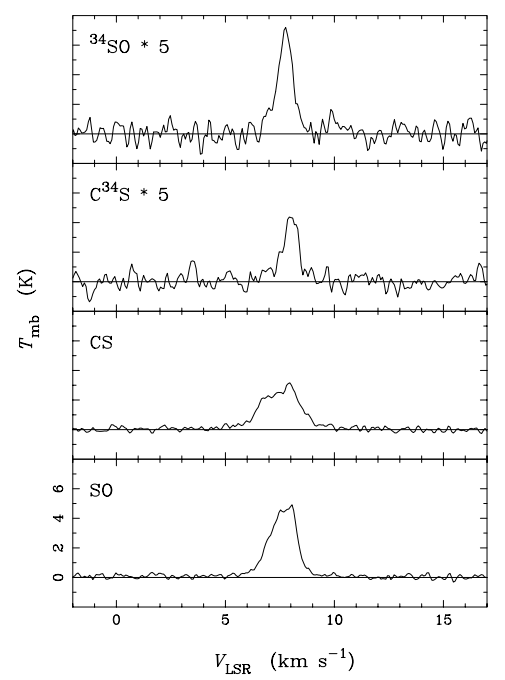

Fig. 10. CS and SO isotopomer spectra. Source name and positions as indicated 
NGC1333 (160.0,-160.0)

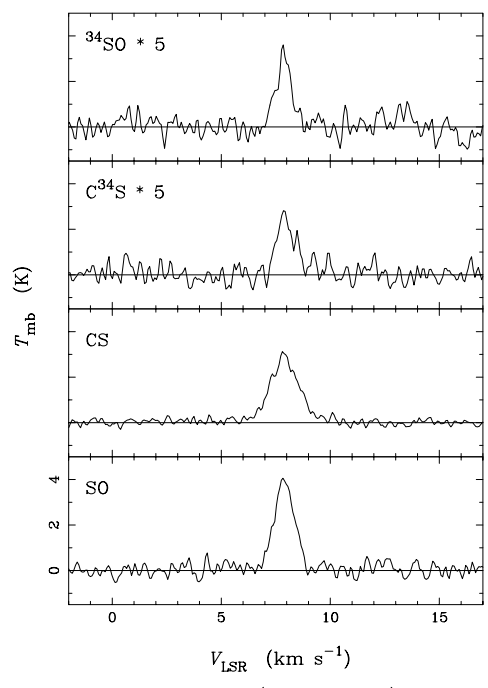

NGC1333 (160.0,-120.0)
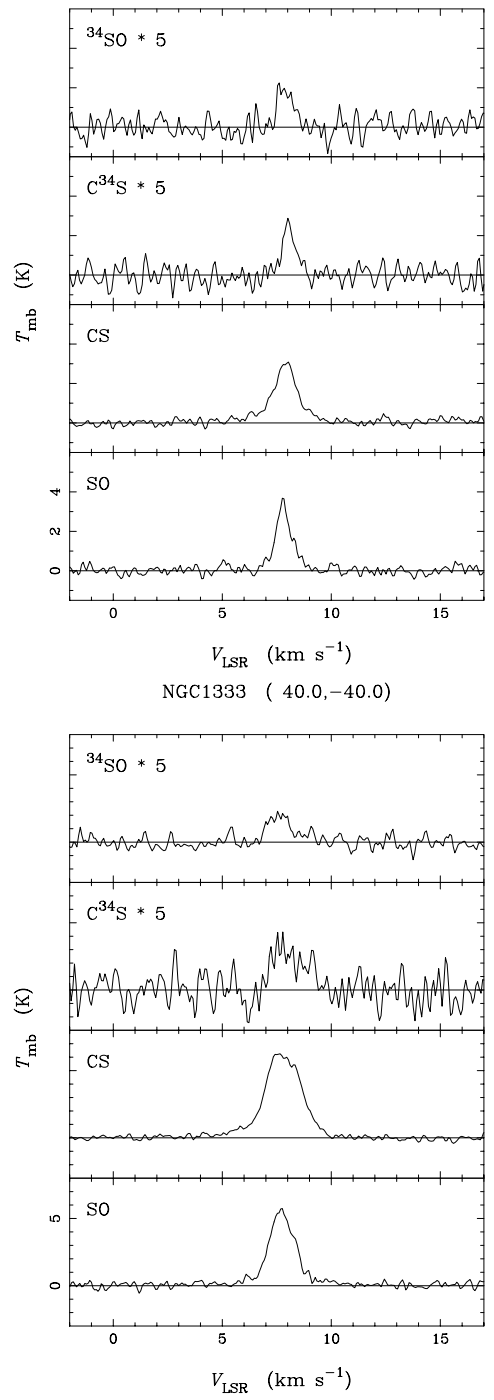

NGC1333 ( $79.9,-120.0)$

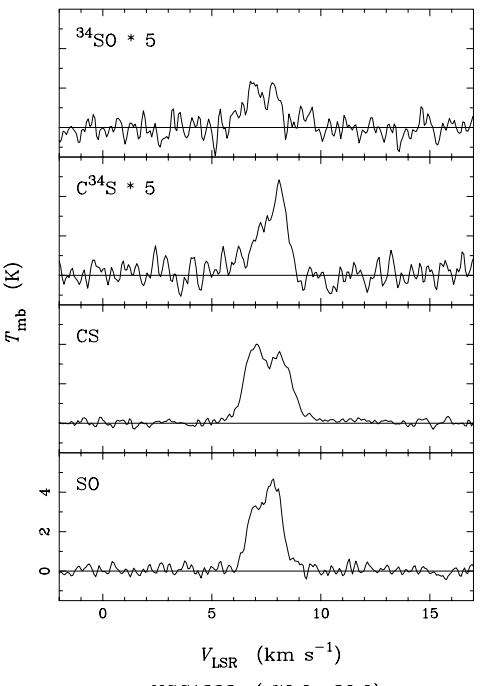

NGC1333 ( 79.9,-80.0)

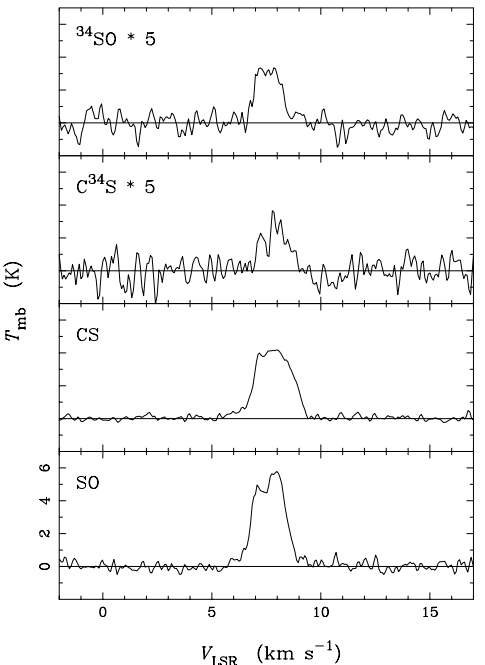

NGC1333 ( 79.9,-40.0)

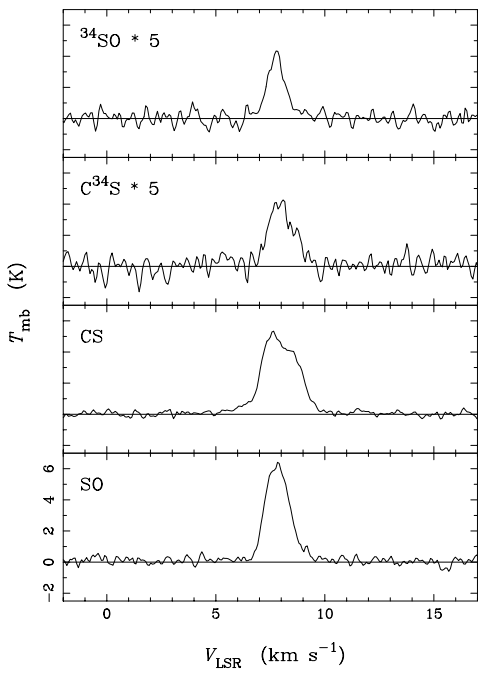

NGC1333 (120.0,-120.0)

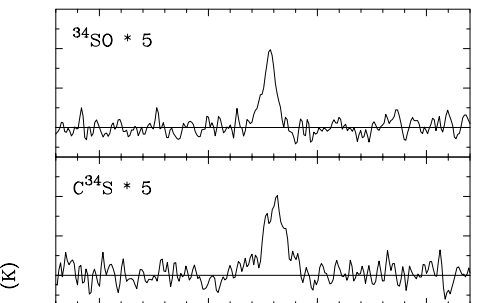

욥

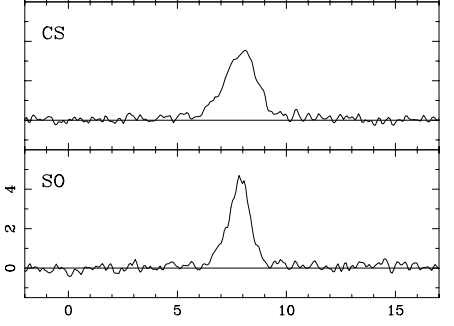

$V_{\mathrm{LSR}}\left(\mathrm{km} \mathrm{s}^{-1}\right)$

NGC1333 (120.0,-80.0)

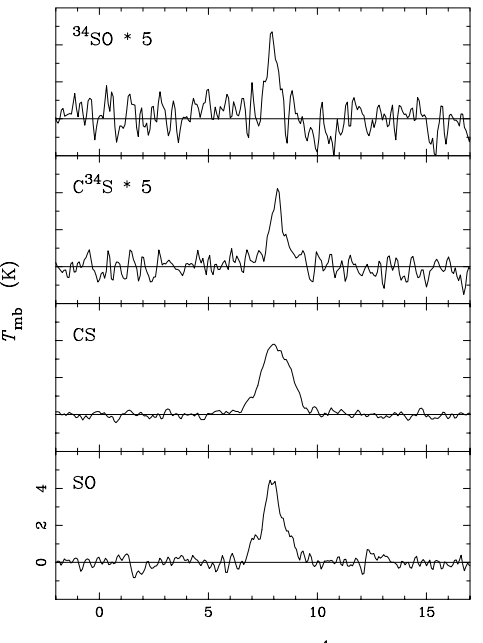

$V_{\mathrm{LSR}}\left(\mathrm{km} \mathrm{s}^{-1}\right)$

NGC1333 (120.0,-40.0)

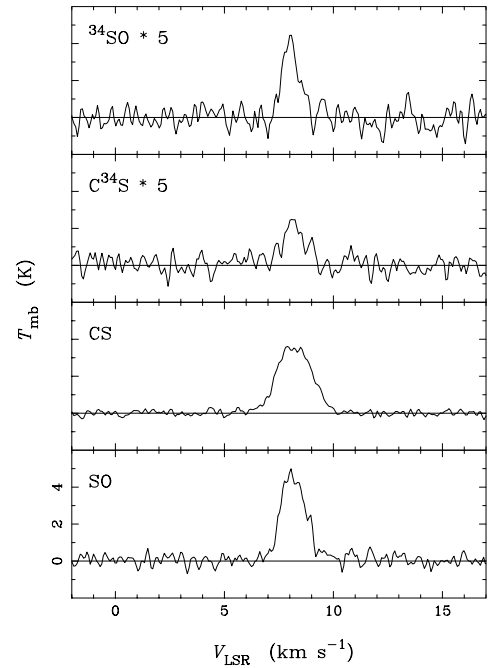

Fig. 11. CS and SO isotopomer spectra. Source name and positions as indicated 
NGC1333 ( $0.0,0.0)$



NGC1333 ( 79.9, 40.0)
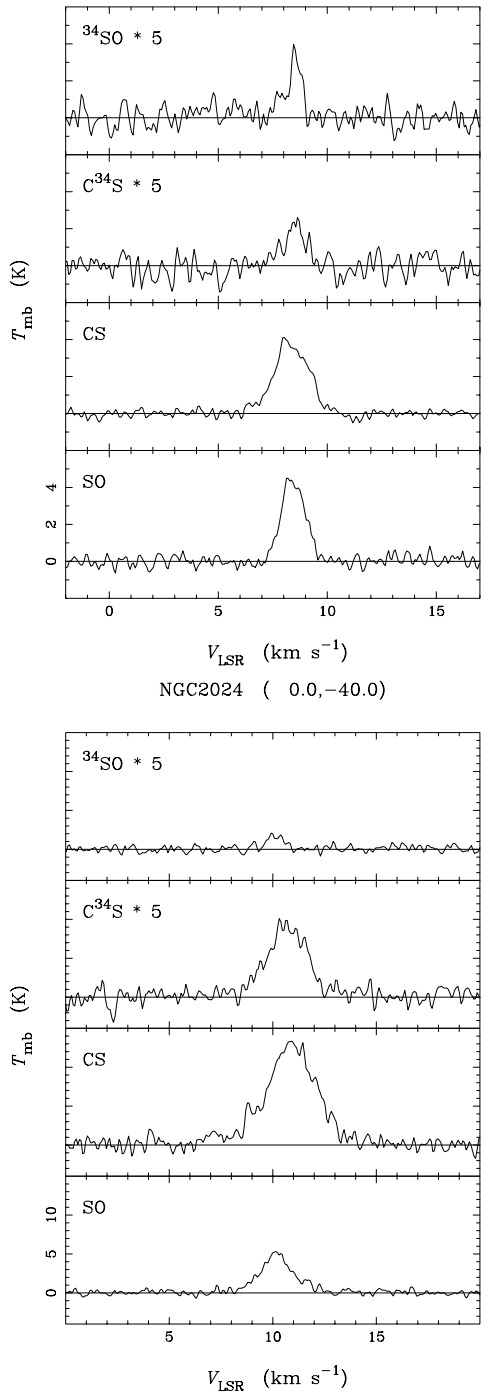

NGC1333 ( $79.9, \quad 0.0)$

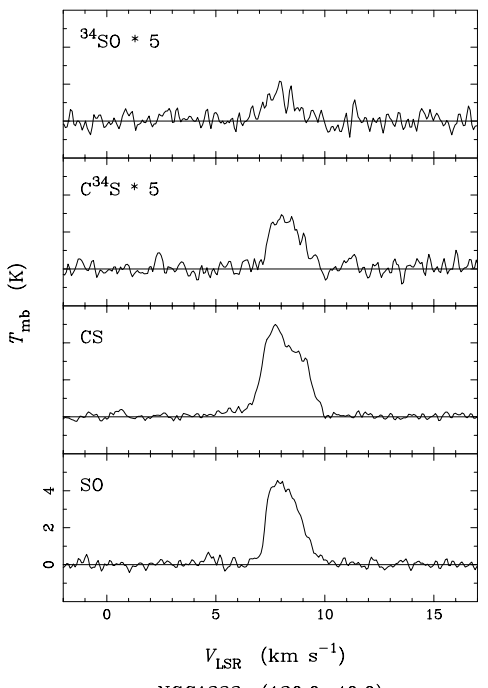

NGC1333 (120.0, 40.0)

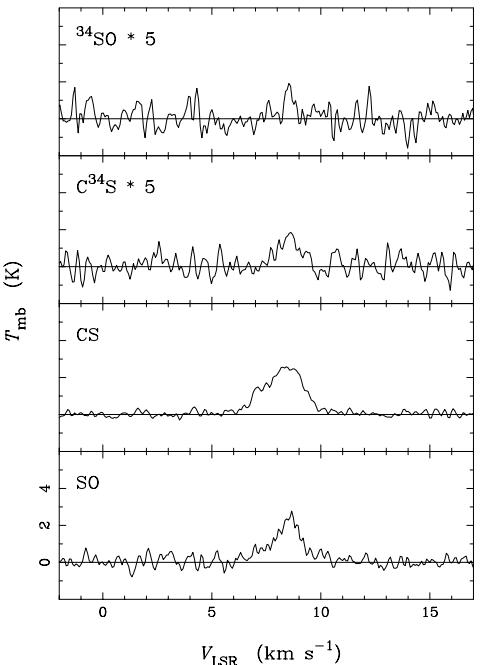

NGC2024 ( $0.0,40.0)$

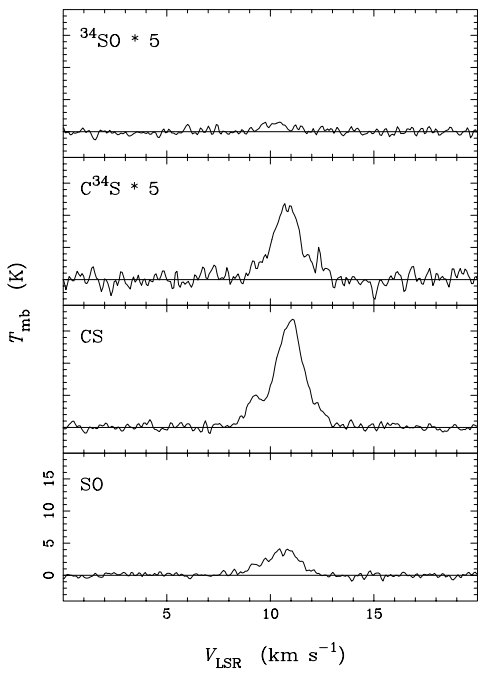

NGC1333 (120.0, 0.0$)$



$V_{\mathrm{LSR}}\left(\mathrm{km} \mathrm{s}^{-1}\right)$

NGC1333 (120.0, 80.0)

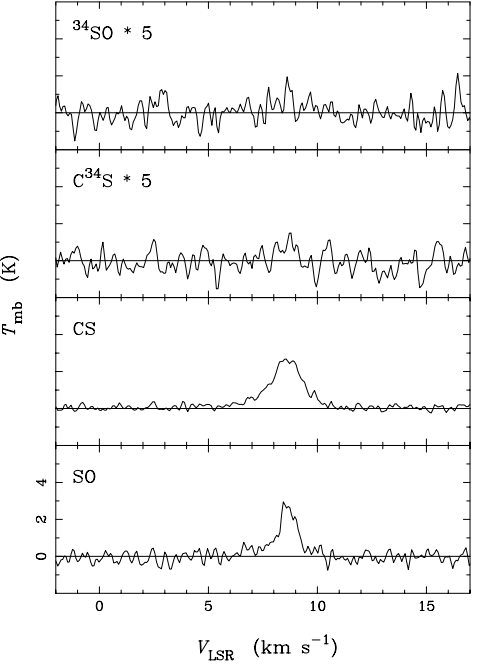

NGC2068 (120.0,-80.0)



Fig. 12. CS and SO isotopomer spectra. Source name and positions as indicated 
NGC2264IR $\left(\begin{array}{ll}0.0, & 0.0\end{array}\right)$

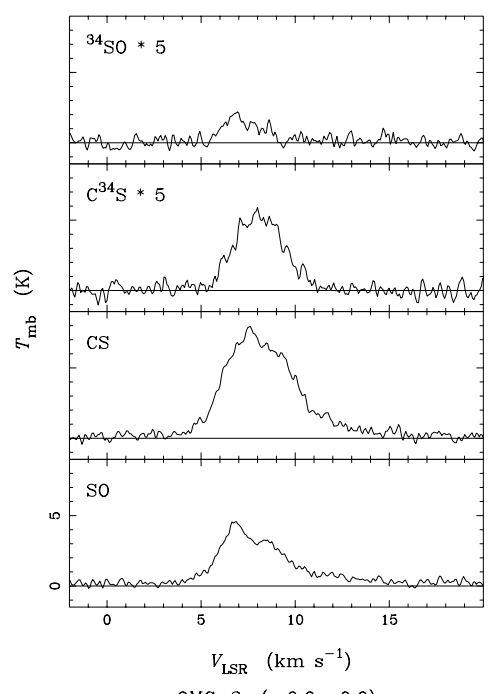

OMC-3 $(0.0,0.0)$
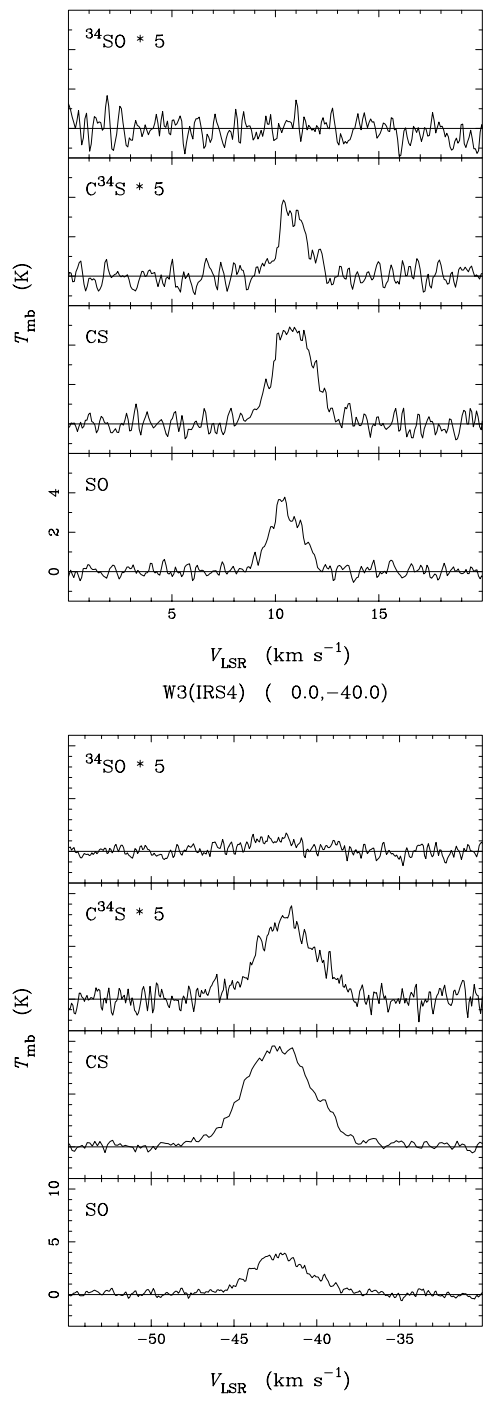

NGC7538 $(0.0,-40.0)$



Orion A $(0.0,-80.0)$



$V_{\mathrm{LSR}}\left(\mathrm{km} \mathrm{s}^{-1}\right)$

W3 $(\mathrm{OH}) \quad(0.0,0.0)$

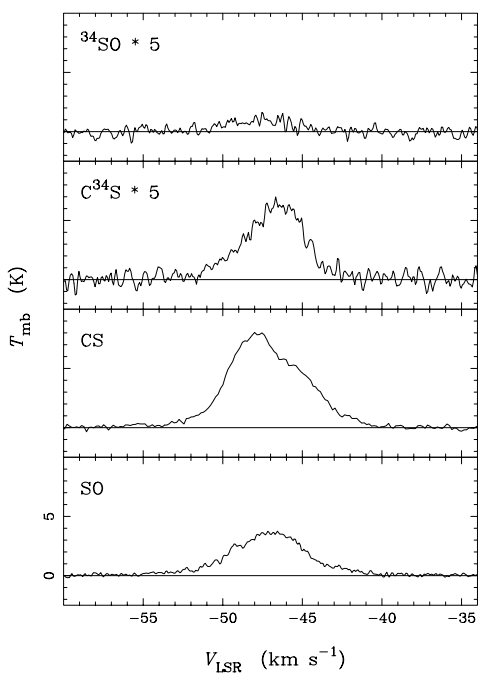

NGC7538 $\quad\left(\begin{array}{ll}0.0, & 0.0\end{array}\right)$
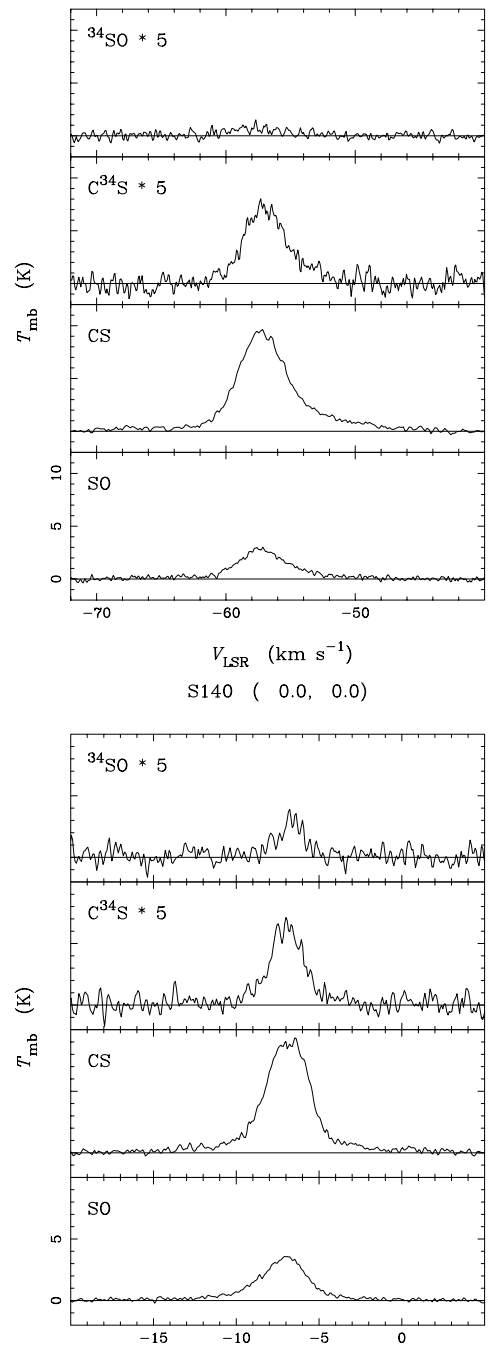

$V_{\mathrm{LSR}}\left(\mathrm{km} \mathrm{s}^{-1}\right)$

W49N $(0.0,0.0)$

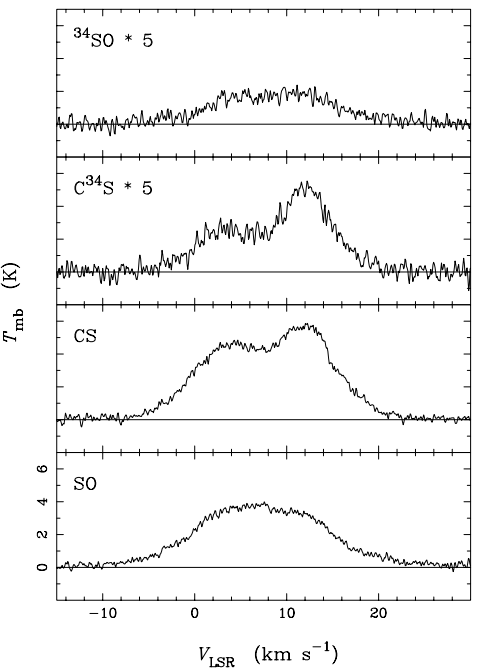

Fig. 13. CS and SO isotopomer spectra. Source name and positions as indicated 

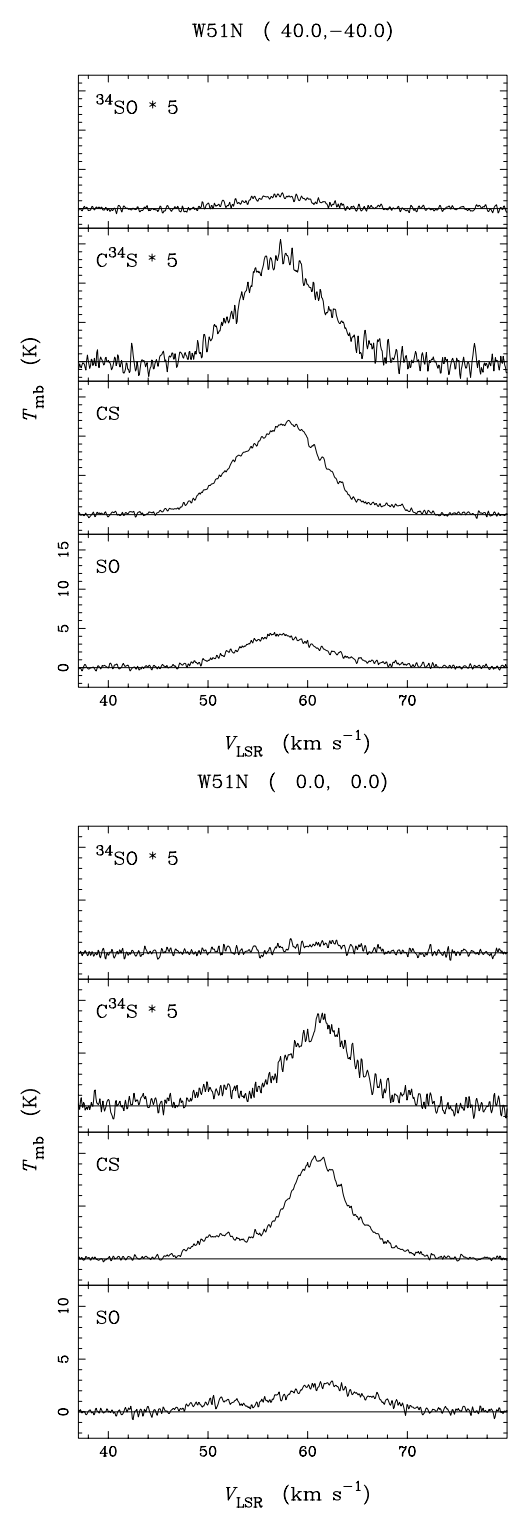

Fig. 14. CS and SO isotopomer spectra. Source name and positions as indicated

CS data. These wings are generally weaker (if seen at all) in SO. The only exceptions are NGC 2264IR and W3(OH) where the wing emission is equally strong in CS and SO. These weak wings are not visible in the rare isotopomer data (the only exception is the $\mathrm{C}^{34} \mathrm{~S}$ line in Orion $\mathrm{A}$ ).

The main isotopomer data will be used in Paper II to derive $\mathrm{SO} / \mathrm{CS}$ integrated intensity ratio maps. To be able to estimate eventual $\mathrm{SO} / \mathrm{CS}$ abundance ratio variations we then have observed the ${ }^{34} \mathrm{SO}\left(3_{2}-2_{1}\right)$ and $\mathrm{C}^{34} \mathrm{~S}(2-1)$ lines in critical positions i.e. where the SO/CS integrated intensity ratio is very high or very low. Since the SO/CS abundance ratio is estimated from the rare isotopomers we can avoid, to a large extent, effects from optical depths and possible outflows. The observed SO, ${ }^{34} \mathrm{SO}, \mathrm{CS}$ and $\mathrm{C}^{34} \mathrm{~S}$ spectra are shown in Figs. $10-14$ and the corresponding integrated intensities are given in Table 2. In

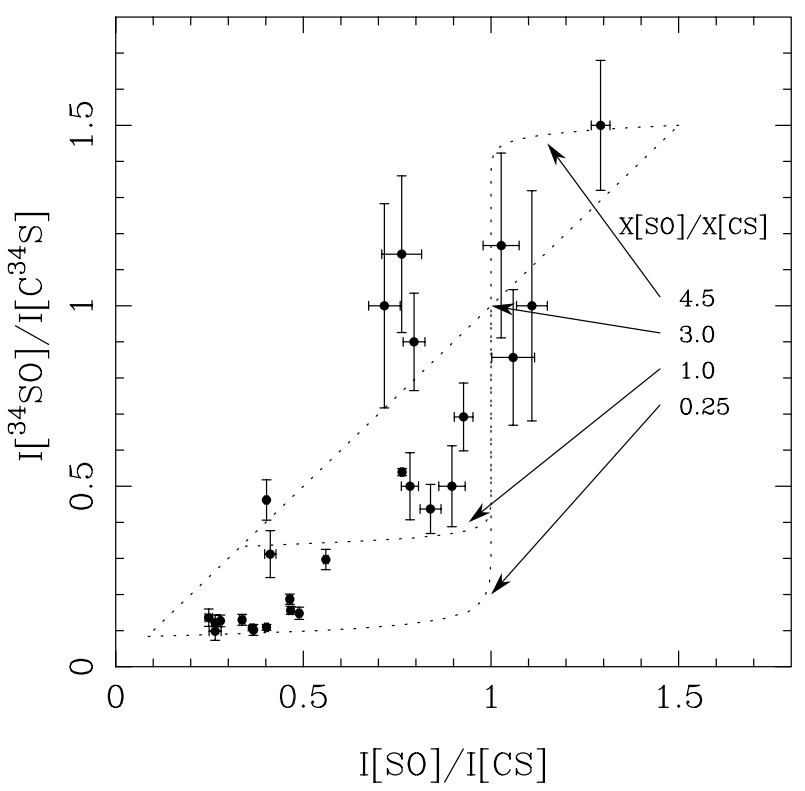

Fig. 15. The integrated intensity ratio $I\left[{ }^{34} \mathrm{SO}\right] / I\left[\mathrm{C}^{34} \mathrm{~S}\right]$ as function of the ratio $I[\mathrm{SO}] / I[\mathrm{CS}]$ (filled circles) for all positions in which all four isotopomers were detected. The error bars correspond to $1 \sigma$ errors. The dotted lines are limits corresponding to the indicated abundance ratio $X[\mathrm{SO}] / X[\mathrm{CS}]$ (see text)

Figs. $10-14$ the $\mathrm{C}^{34} \mathrm{~S}$ and ${ }^{34} \mathrm{SO}$ spectra have been multiplied with a factor 5. In the cases of NGC 2071 and Orion A the residual integrated intensity is tabulated in Table 2.

In order to check the consistency of the data further we have used those entries in Table 2, for which we have reliable detections in all four isotopomers, to plot the integrated intensity ratio $I\left[{ }^{34} \mathrm{SO}\right] / I\left[\mathrm{C}^{34} \mathrm{~S}\right]$ as function of the ratio $I[\mathrm{SO}] / I[\mathrm{CS}]$, see Fig. 15 . Here we see a clear correlation between the two ratios (as would be expected). Also shown in Fig. 15 (as dotted lines) are limits for SO/CS abundance ratios in the range 0.25 to 4.5 . All data points, but one, fall in the region spanned by this range if we allow the ratios to vary within their $1 \sigma$ errors. The error estimation of the ratios is discussed thoroughly in Paper II (Sect. 2.1) in conjunction with the ratio maps. The limits have been calculated assuming a ${ }^{32} \mathrm{~S} /{ }^{34} \mathrm{~S}$ ratio of 22 (Wilson \& Rood 1994) and that the SO optical depth is a factor of three lower than the optical depth of the CS line if the SO and CS abundances are equal (due to the threefold spin multiplicity of SO, see Paper II).

\section{Discussion}

As is evident already from a visual comparison of the $\mathrm{SO}$ and CS maps displayed in Figs. 1-9 rather large variations of SO/CS integrated intensity ratio are apparent within and between the sources. Moreover, as can be seen in Fig. 15, the intensity ratio $I[\mathrm{SO}] / I[\mathrm{CS}]$ can in general be used as a tool to find positions where SO/CS abundance variations are likely to occur. In fact, using the results in 
Fig. 15 we can estimate that the SO/CS abundance ratio varies between $0.25-4.5$. This crude estimate indeed reflects large abundance variations as will be advocated, based upon a more thorough analysis, in Paper II.

In a subsequent Paper III (Olofsson et al., in prep.) we plan to derive the true abundance variations with respect to $\mathrm{H}_{2}$ in all the sources catalogued in this paper. The $\mathrm{H}_{2}$ column density mapping information is currently being accumulated in terms of $\mathrm{C}^{18} \mathrm{O}(1-0)$ mapping.

Acknowledgements. We thank the referee, L. Pagani, for constructive comments on the manuscript. The authors wish to thank the Swedish National Space Board (Rymdstyrelsen) for substantial Odin astronomy funding. PB and ÅH also acknowledge partial support by the Swedish National Science Research Council (NFR).

\section{References}

Bergin E.A., Langer W.D., Goldsmith P.F., 1995, ApJ 441, 222

Bergin E.A., Goldsmith P.F., Snell R.L., Langer W.D., 1997, ApJ 482, 316

Blake G.A., Sandell G., van Dishoeck E., et al., 1995, ApJ 441, 689

Castets A., Langer W.D., 1995, A\&A 294, 835

Chernin L.M., Masson C.R., Fuller G.A., 1994, ApJ 436, 741

Combes F., Wiklind T., 1995, A\&A 303, L61

Combes F., Casoli F., Encrenaz P., Gerin M., Laurent C., 1991, A\&A 248, 607

Combes F., Wiklind T., Nakai N., 1997, A\&A 327, L17

Edwards S., Snell R.L., 1984, ApJ 281, 237

Ehrenfreund P., van Dishoeck E.F., 1998, Advances in Space Research v. 21, Issue 1, 15

Friberg P., 1984, A\&A 132, 265

Fuente A., Cernicharo J., Gracia-Burillo S., Tejero J., 1993, A\&A 275, 558

Graedel T.E., Langer W.D., Frerking M.A., 1982, ApJS 48, 321

Hjalmarson A., 1997, in: CO: Twenty-Five Years of MillimeterWave Spectroscopy, Latter W.B., Radford S.J.E., Jewell P.R., Mangum J.G., Bally J. (eds.). Kluwer Academic Publishers, Dordrecht, p. 227
Lada E.A., 1992, ApJ 393, L25

Langer W.D., Castets A., Lefloch B., 1996, ApJ 471, L111

Liseau R., Sandell G., Knee L.B.G., 1988, A\&A 192, 153

Mangum J.G., Wootten A., 1993, ApJS 89, 123

Maréchal P., Pagani L., Langer W.D., Castets A., 1997, A\&A 318,252

Melnick G.J., Stauffer J.R., Ashby M.L.N., et al., 1999, BAAS 194,4708

Millar T.J., Herbst E., 1990, A\&A 231, 466

Millar T.J., Nejad L.A.M., 1985, MNRAS 217, 517

Millar T.J., Herbst E., Charnley S.B., 1991, ApJ 369, 147

Millar T.J., Farquhar P.R.A., Willacy K., 1997, A\&AS 121, 139

Mundy L.G., Snell R.L., Evans II N.J., Goldsmith P.F., Bally J., 1986, ApJ 306, 670

Nilsson A., Hjalmarson A., Bergman P., Millar T.J., 2000, A\&A (in press) (Paper II)

Olofsson G., Pagani L., Tauber J., et al., 1998, A\&A 339, L81

Olofsson H., Elldér J., Hjalmarson Å., Rydbeck G., 1982, A\&A 113, L1

Pagani L., Langer W.D., Castets A., 1993, A\&A 274, L13

Patel N.A., Goldsmith P.F., Snell R.L., Hezel T., Xie T., 1995, ApJ 447, 721

Plume R., Jaffe D.T., Evans II N.J., 1992, ApJS 78, 505

Prasad S.S., Huntress W.T., 1982, ApJ 260, 590

Scoville N.Z., Sargent A.I., Sanders D.B., et al., 1986, ApJ 303, 416

Serabyn E., Güsten R., Schulz A., 1993, ApJ 413, 571

Snell R.L., Mundy L.G., Goldsmith P.F., Evans II N.J., Erickson N.R., 1984a, ApJ 276, 625

Snell R.L., Scoville N.Z., Sanders D.B., Erickson N.R., 1984b, ApJ 284, 176

Vandenbussche B., Ehrenfreund P., Boogert A.C.A., et al., 1999, A\&A 346, L57

Wilking B., Mundy L., McMullin J., Hezel T., Keene J., 1993, AJ 106, 250

Wilner D.J., Welch W.J., 1994, ApJ 427, 898

Wilson T.L., Rood R., 1994, ARA\&A 32, 191

Zhou S., Evans II N.J., Güsten R., Mundy L.G., Kutner M.L., 1991, ApJ 372, 518

Zhou S., Butner H.M., Evans II N.J., et al., 1994, ApJ 428, 219 